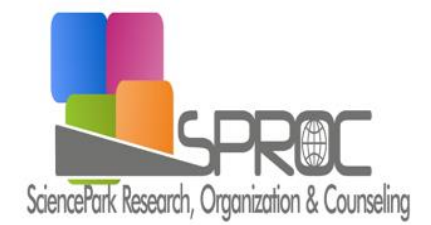

Global Journal of
Psychology Research

http://sproc.org/ojs/index.php/gjpr

\author{
Volume 05, Issue 2, (2015)
}

Table of Contents

Message from the Editors

\title{
Dear Readers
}

It is the great honor for us to publish fifth issue of Global Journal of Psychology Research

The scope of the Global Journal of Psychology Research includes, but is not limited to; the following major areas as they relate to Psychology as Clinical Psychology, Developmental Psychology, Social Psychology, Experimental Psychology, Industrial and Organization Psychology, Traffic Psychology, Forensic Psychology, Psychometric Psychology, Sports Psychology, Health Psychology, Educational Psychology, Media Psychology, Neuroscience Psychology. The major criteria in the review and the selection process concern the significance of the contribution to the area of psychology.

Axiology of socio-humanitarian cognitive, group therapy, psychomotor and cognitive recovery and psychologycal war have been included into this issue. The topics of the next issue will be different. You can make sure that we will be trying to serve you with our journal with a rich knowledge in which different kinds of topics are discussed in 2015 Volume.

A total of seven (13) manuscripts were submitted for this issue and each paper has been rigor peer reviewed by the reviewers specialized in the related field. At the end of the review process, a total of two (4) high quality research papers were selected and accepted for publication.

We thank all the contributors who helped us to publish this issue.

Best regard

Prof. Dr. Tulay Bozkurt

Editor - in Chief 